\title{
Involvement of protein kinase C pathway in UVC-stimulated phospholipase D2 activity in Vero 76 cells
}

\author{
Sungyeul Kim, Myung Sun $\mathrm{Choi}^{2}$ \\ and Myung-Un Choi ${ }^{1,3}$
}

\author{
${ }^{1}$ School of Chemistry \\ Seoul National University \\ Seoul 151-747, Korea \\ ${ }^{2}$ Department of Radiation Oncology \\ Korea University College of Medicine \\ Seoul 136-705, Korea \\ ${ }^{3}$ Corresponding author. Tel, 82-2-880-6657; \\ Fax, 82-2-871-4927; E-mail, muchoi@snu.ac.kr
}

\section{Accepted 17 August 2005}

Abbreviations: BAPTAAM, 1,2-Bis (2-aminophenoxy) ethane-N,N, N',N-tetraacetic acid tetrakis (acetoxymethyl ester); $L O O H$, lipid hydroperoxide; PA, phosphatidic acid; PAL, palmific acid; PBt, phosphatidylbutanol; PKC, protein kinase C; PLD, phospholipase D; $R O S$, reactive oxygen species

\begin{abstract}
Phospholipase $D$ (PLD) activity is known to be related to oxidant-induced cellular signaling and membrane disturbance. Previously, an induction of PLD activity in various cell lines by $X$-ray irradiation was observed. In this study, we examined the effect of UVC radiation on the PLD activity in Vero 76 cells. At a dose of $10 \mathrm{~kJ} / \mathrm{m}^{2}$ of UVC irradiation, the PLD activity was stimulated approximately 10-fold over the basal activity. This UVC-induced PLD activity was found to be dependent on the presence of extracellular calcium and was inhibited by catalase as well as amifostine - an intracellular thiol antioxidant. Pretreatments with Ro32-0432 - a selective inhibitor of protein kinase C (PKC) - and downregulation of PKC by preincubation of phorbol 12-myristate 13-ace tate significantly inhibited the UVC-induced PLD activity. UVC-stimulated PLD activity was observed only in murine PLD2 (mPLD2)-transfected Vero 76 cells and not in human PLD1 (hPLD1)-transfected cells. Transient incorporation of PKC with MPLD2 and the phosphorylation of mPLD2 by $\alpha$ and $\beta$ forms of PKC by UVC irradiation were observed. These results suggest that the UVC-stimulated PLD activity in Vero 76 cells is mediated through transient phosphorylation of PLD2 by the translocation of PKC to PLD2.
\end{abstract}

Keywords: phospholipase D; protein kinase C; reactive oxygen species; ultraviolet rays

\section{Introduction}

UVC - $100 \mathrm{~nm} 280 \mathrm{~nm}$ - is known to produce superoxide radicals, resulting in hydrogen peroxide generation. The hydrogen peroxide-derived hydroxyl radical (HO-) reacts with cellular proteins and membrane lipids that provoke various physiological cellular responses (Girotti, 1998). The prominent targets of oxidant attack are unsaturated phospholipids, glycolipids, and cholesterol in cell membranes and other cellular organelles. These attacks result in lipid hydroperoxidation that disturbs the membrane structures and induces various physiological disorders (Halliwell and Gutteridge, 1989). Physiological events such as detoxification processes, apoptosis, or necrotic cell death are dependent on the amount of lipid hydroperoxide $(\mathrm{LOOH})$ present. At a relatively low dose of $\mathrm{LOOH}$, oxidative injury may trigger a series of cytoprotective responses, e.g., induction of GSH and antioxidant proteins such as glutathione peroxidase, catalase, or heme oxygenase (Girotti, 2001). At a moderate dose of $\mathrm{LOOH}$, peroxide induces apoptosis, which is characterized by cell shrinkage and the internucleosomal fragment of nuclear DNA. At a high dose of $\mathrm{LOOH}$, the oxidative stress triggers membrane lysis associated with gross structural damage and random DNA fragmentation.

Oxidant-induced lipid signalings are usually associated with several enzymes such as phospholipase A2, phosphoinositide phospholipase $\mathrm{C}$, and phospholipase $\mathrm{D}$ in various types of cells (Weigel et al., 1997; Shen et al., 2001). Phospholipase D activation, in particular, has been reported to be an im portant cellular signaling process, which leads to the generation of phosphatidic acid as a potential second messenger (Rydzewska et al., 1996). There exist two mammalian PLD isoforms (PLD1 and PLD2) that occur as splice variants (Frohman et al., 1999). PLD1 appears to be localized in the Golgi or perinuclear vesicular structure (Liscovitch et al., 1999; Freyberg et al., 2001; Choi et al., 2002; Jang et al., 2004), whereas PLD2 appears to be associated with the plasma membrane (Choi et al., 2002; Exton, 2002; Sarri et al., 2003). PLD1 is known to be activated by protein kinase $\mathrm{C}(\mathrm{PKC})$, ADP-ribo- 
sylation factor, RalA, and RhoA in the presence of phosphatidylinositol 4, 5-bisphosphate. However, it has been reported that PLD2 is not activated by PLD1 activators (Colley et al., 1997). In vivo activity of PLD2 is activated by factors that cause membrane disturbance, such as oleate (Sarri et al., 2003) and mastoparan (Chahdi et al., 2003).

It has been reported that the PLD activity that is stimulated by extracellular treatment of reactive oxygen species (ROS) is dependent on various protein kinase pathways in several cell lines. For instance, p38 MAPK (mitogen-activated protein kinase) and PKC mediated the activation of PLD by pervanadate and diperoxovanadate (Natarajan et al., 1996; Min et al., 2002; Kim et al., 2003). In astrocytes and fibroblasts, $\mathrm{H}_{2} \mathrm{O}_{2}$-induced PLD1 stimulation was inhibited by PKC inhibitors and was almost completely suppressed by PKC downregulation (Min et al., 1998; Servitja et al., 2000). However, in other cell lines such as PC12 and the vascular smooth muscle cells, which exhibit only PLD2 activity, PLD activation was shown to be independent of PKC activity (Ito et al., 1997; Taher et al., 1998). On the other hand, in the lymphocytic leukemic L1210 cells and the vascular smooth muscle cells, $\mathrm{H}_{2} \mathrm{O}_{2}$-induced PLD stimulation was reported to be dependent on PKC (Lee et al., 2000; Kim et al., 2004). Therefore, the involvement of PKC in ROS-induced PLD activation remains controversial.

Previously, we investigated the effects of irradiation on PLD activity in various cultured cells and discovered that the PLD activity of Vero 76 (monkey kidney endothelial) cells was extremely sensitive to oxidative stress that was induced by irradiation (Kim et al., 1997). In this report, PLD in the Vero 76 cells was further characterized by UVC irradiation, and a potential correlation between PLD activation and intracellular ROS was explored. The UVC-stimulated PLD activity is effectively inhibited by antioxidants and is quite sensitive to the expressed PLD2 isoform. We also demonstrated the transient phosphorylation of PLD2 by PKC and that PKC interacts with the transfected PLD2 isoform.

\section{Materials and Methods}

Materials
$\left[{ }^{9,10-3} \mathrm{H}(\mathrm{N})\right]$ palmitic acid $\left.\left({ }^{3} \mathrm{H}\right] \mathrm{PAL}\right)$ was purchased
from Dupont NEN (Boston, MA). [ $\left.{ }^{3} \mathrm{H}\right]$ dipalmitoyl
phosphatidylcholine (DPPC) was kindly prepared by
S. J. Lee (Seoul National University, Seoul, Korea).
Catalase, amifostine, PD098059, SB203581, wort-
manin, genistein, Ro32-0432, GF109203X, phobol
12-myristate 13-acetate, anti P-ser antibody, BAPTA/
AM, and Z-VAD-fmk were purchased from Sigma
(St. Louis, MO). The cell culture medium, Dulbecco's modified Eagle's medium (DMEM), Lipofectamine and PLUS Reagent were purchased from Invitrogen (Carlsbad, CA). 2'-7'-Dichlorodihydrofluorescein diacetate (H2DCFDA) was purchased from Microprobe (Eugene, OR). Anti-PLD1 antibody and anti-PLD2 antibody were purchased from Biosource (Camarillo, CA). Anti-P-thr, anti-P-tyr, anti-HA antibody, antiPKC (MC5), anti-PKC $\alpha$ (A-3), and anti-PKC $\beta 1$ (E-3) antibody were obtained from Santa Cruz Biotechnology (Santa Cruz, CA). Precoated TLC gel (silica gel $60 \mathrm{~F}_{254}$ ) was purchased from Merck (Darmstadt, Germany). Human PLD1b (hPLD1b) and mouse PLD2 (mPLD2) cDNAs subcloned into a pCGN vector was kindly provided by Dr. Sue Goo Rhee (National Institutes of Health, Bethesda, MD). Phosphatidylbutanol (PBt) was prepared from phosphatidylcholine (PC) by using PLD from Streptomyces $s p$. according to the previously described method (Jung et al., 1989).

Cell culture, isotope labeling, and UVC irradiation Vero 76 (monkey kidney endothelial) cells were grown in HEPES- $(20 \mathrm{mM})$ buffered DMEM medium supplemented with $10 \%(\mathrm{v} / \mathrm{v})$ FBS. The confluent cells were labeled with $\left.{ }^{3} \mathrm{H}\right] \mathrm{PAL}(1.0-2.0 \mu \mathrm{Ci} / \mathrm{ml})$ for 3 $\mathrm{h}$ in a serum-free DMEM medium containing $0.3 \%$ (w/v) fatty acid-free bovine serum albumin. After washing with phosphate-buffered saline (PBS), the cells were preserved with the serum-free DMEM medium containing inhibitors and incubated for 30 min at $37^{\circ} \mathrm{C}$. Cells overlaid with serum-free DMEM were exposed to an indicated dose of UVC with a UVC 500 UV crosslinker (Hoefer, Austria).

\section{Assay of PLD activity}

The PLD activity in intact cells was determined by measuring PBt, the unique transphosphatidylation product of PLD in the presence of n-butanol, as previously described (Lee et al., 1998). [ $\left.{ }^{3} \mathrm{H}\right] \mathrm{PAL}-$ labeled cells were resuspended in the assay medium supplemented with $0.3 \%$ n-butanol. After UVC irradiation at $37^{\circ} \mathrm{C}$, the $\left[{ }^{3} \mathrm{H}\right] \mathrm{PBt}$ that was produced was separated on a TLC plate by using a solvent system that comprised ethylacetate/isooctane/acetic acid/water $(13 / 2 / 3 / 10)$ and counted in a liquid scintillation counter (Wallac 1409; Turku, Finland).

For the PLD assay with cell lysates, the cell pellet was disrupted by using a microprobe-type ultrasonicator (Danbury, CT) in PBS-containing protease inhibitor cocktails (Boehringer Manheim, Germany), and cell lysates were prepared by harvesting the supernatant of microcentrifugation at $10,000 \mathrm{rpm}$ for $3 \mathrm{~min}$. ARF-dependent PLD activity was essentially assayed according to the method described by 
Brown et al., (1993) with slight modifications. A 20- $\mu$ l aliquot of mixed lipid vesicles $\left(\mathrm{PE} / \mathrm{PIP}_{2}\right.$ /egg $\mathrm{PC}$, molar ratio $16 / 1.4 / 1$ ) with $0.2 \mu \mathrm{Ci}$ of $\left[{ }^{3} \mathrm{H}\right] \mathrm{DPPC}$ was added to $50 \mu$ of the assay solution containing 50 $\mathrm{mM}$ HEPES (pH 7.4), $3 \mathrm{mM}$ EGTA, $80 \mathrm{mM} \mathrm{KCl}, 1$ $\mathrm{mM}$ DTT, $3.0 \mathrm{mM} \mathrm{MgCl}$, and $2.0 \mathrm{mM} \mathrm{CaCl}_{2}$. Reaction mixtures also contained $100 \mu \mathrm{M}$ GTP $\gamma \mathrm{S}, 1$ $\mu \mathrm{M}$ ARF, $0.3 \% \mathrm{n}$-butanol, and $30 \mu \mathrm{g}$ of the cell lysates; this was incubated for $60 \mathrm{~min}$ at $37^{\circ} \mathrm{C}$. The separation and measurement of $\left[{ }^{3} \mathrm{H}\right] \mathrm{PBt}$ were performed by the method described above.

\section{Transfection of PLD vector}

Transient expression of hPLD1b and mPLD2 cDNAs to Vero 76 cells was performed using lipofectamine PLUS in accordance with the manufacturer's instructions. Subconfluent Vero 76 cells that were maintained at room temperature for $30 \mathrm{~min}$ in $1 \mathrm{ml}$ of serum-free DMEM medium were previously treated with DNA complex containing $1 \mu \mathrm{g}$ of DNA, $6 \mu \mathrm{l}$ of PLUS Reagent, and $4 \mu$ of lipofectamine. After incubation for $4 \mathrm{~h}, 1 \mathrm{ml}$ of fresh culture medium containing $20 \%$ FBS was added. The PLD in Vero 76 cells was assayed and blotted after $24 \mathrm{~h}$.

\section{Subcellular fractionation}

Subcellular fractionation of the Vero 76 cell lysates was carried out as described by $\mathrm{Hu}$ and Exton with slight modifications. After UVC irradiation, 100-mm plates of Vero 76 cells were washed twice with ice-cold PBS and then harvested using lysis buffer (25 mM HEPES, pH 7.2, 10\% glycerol, 1 mM EDTA, $1 \mathrm{mM}$ EGTA, $1 \mathrm{mM}$ dithiothreitol, and protease inhibitor mixture) with a rubber policeman. After a 10 -s sonication, the cell lysates were first centrifuged at $500 \times g$ for $10 \mathrm{~min}$ to remove the unbroken cells. The supernatant was then centrifuged at $120,000 \times g$ for $45 \mathrm{~min}$ at $4^{\circ} \mathrm{C}$ with a Beckmann ultracentrifuge to separate the cytosolic and crude membrane fractions.

\section{Measurement of intracellular reactive oxygen species}

ROS produced in the intracellular space of the Vero 76 cells was quantized by measuring the fluorescence of $2^{\prime}-7^{\prime}$-dichlorodihydrofluorescin - an intracellular localized ROS sensor. The Vero 76 cells were incubated with HBSS buffer containing $20 \mu \mathrm{M} \mathrm{2} 2^{\prime}-$ $7^{\prime}$-dichlorodihydrofluorescin diacetate (H2DCFDA) for $20 \mathrm{~min}$ at $37^{\circ} \mathrm{C}$. The cells were washed twice with HBSS to separate the free H2DCFDA and then resupplied with serum-free DMEM for UVC irradiation. After UVC irradiation, fluorescence changes were analyzed by Zeiss fluorescence microscopy and quantized with an SFM 25 Spectro fluorometer
(Kontron, Italy). The excitation wavelength was $\mathbf{5 2 0}$ $\mathrm{nm}$, and the emission wavelength was $604 \mathrm{~nm}$.

\section{Immunoprecipitation and Western blotting}

Vero 76 cells that were cultured in a $100-\mathrm{mm}$ plate were transfected as previously described. The cells were washed twice with ice-cold PBS buffer and harvested using immunoprecipitation buffer containing $20 \mathrm{mM}$ Tris, $137 \mathrm{mM} \mathrm{NaCl}, 1 \mathrm{mM}$ EDTA, $1 \%$ NP-40, 0.5\% Triton X-100, $2 \mu \mathrm{g} / \mathrm{ml}$ leupeptin, $1 \mu \mathrm{g} / \mathrm{ml}$ aprotinin, $1 \mathrm{mM}$ PMSF, and $1 \mathrm{mM}$ vanadate. The cell suspension was sonicated for $10 \mathrm{~s}$ and then centrifuged at $10,000 \mathrm{rpm}$ for $5 \mathrm{~min}$ in order to pellet the detergent-insoluble fraction. One milligram of the supernatant was incubated overnight with $2 \mu \mathrm{gg}$ of anti-PLD2 antibody or anti-HA antibody in the presence of $20 \mu \mathrm{l}$ of protein A/G beads. The immunoprecipitates were washed three fimes with ice-cold DPBS and resuspended with the Laemmli sampling buffer. The samples were analyzed by SDS-PAGE and transferred to a nitrocellulose membrane. The membrane was blotted with $5 \%$ skimmed milk in TTBS solution, incubated with a primary antibody, and then with an HRP-conjugated antibody or an AP-conjugated antibody. The bands were detected using an enhanced chemiluminescence kit (Pierce, Rockford, IL).

\section{Results}

\section{Activation of PLD by UVC irradiation}

We investigated the effect of UVC on the activation of PLD in Vero 76 cells. Cultured cells overlaid with serum-free DMEM were exposed to various doses of UVC and incubated for $30 \mathrm{~min}$ at $37^{\circ} \mathrm{C}$. As shown in Figure $1 \mathrm{~A}$, exposure of Vero 76 cells to $5 \mathrm{~kJ} / \mathrm{m}^{2} \sim 20$ $\mathrm{kJ} / \mathrm{m}^{2}$ resulted in an increase greater than 10 -fold of the intact cell PLD activity, whereas at doses above $20 \mathrm{~kJ} / \mathrm{m}^{2}$, the induction of PLD activity was reduced.

The PLD activity stimulated by UVC irradiation (10 $\mathrm{kJ} / \mathrm{m}^{2}$ ) was assayed at 5 -min intervals in order to characterize time dependence (Figure 1B). This PLD activity was increased within $5 \mathrm{~min}$ after $10 \mathrm{~kJ} / \mathrm{m}^{2}$ of UVC irradiation. Major stimulation of PLD activity occurred during the second period of 5-10 $\mathrm{min}$. The activity level then gradually decreased to the basal activity after approximately $30 \mathrm{~min}$. Cumulative $\mathbf{5}$ min-interval PLD activity was replotted as timedependent PLD activity (Figure 1B inset). The cumulative quantity of $\left[{ }^{3} \mathrm{H}\right] \mathrm{PBt}$ in Vero 76 cells during the 30 -min incubation period reached approximately $1 \%$ of the total lipids. This amount is similar to that of the PLD activity shown in Figure $1 \mathrm{~A}$ with the same dose of UVC during the 30-min incubation period. 
A

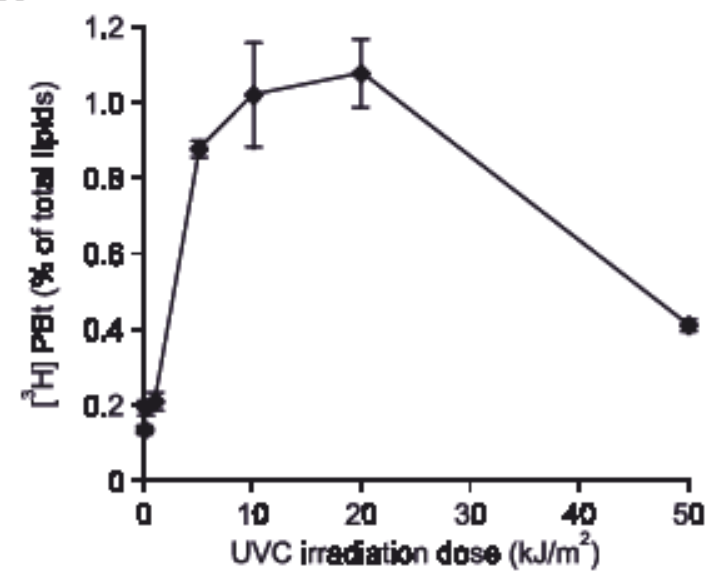

B

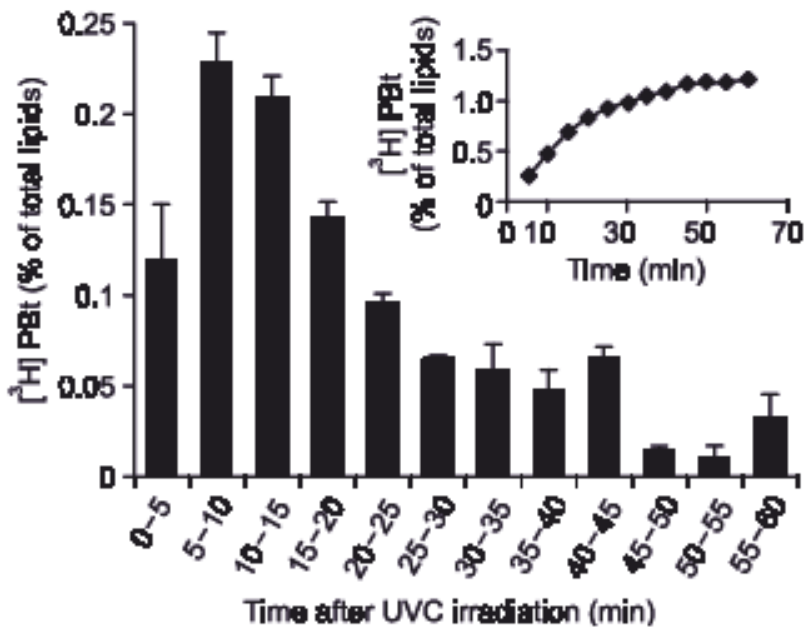

Figure 1. Effect of UVC on the PLD activity in Vero 76 cells. (A) $\left.{ }^{3} \mathrm{H}\right]$ PAL-tabeled Vero 76 cells were irradiated with the indicated dose of UVC and incubated for $30 \mathrm{~min}$ at $37^{\circ} \mathrm{C}$ in the presence of $0.3 \%$ of $n$-butanol. (B) PLD activity of Vero 76 cells irradiated with $10 \mathrm{~kJ} / \mathrm{m}^{2} \mathrm{UVC}$, followed by incubation at the indicated time intervals. The 5-min interval PLD activity was obtained after subtraction of the basal activity. (inset) The 5-min interval PLD activity was plotted cumulafively. The radioactivity incorporaled inb PBt was measured as described under Malerials and Methods. The data presented are the mean $\pm \mathrm{SD}$ in triplicate.

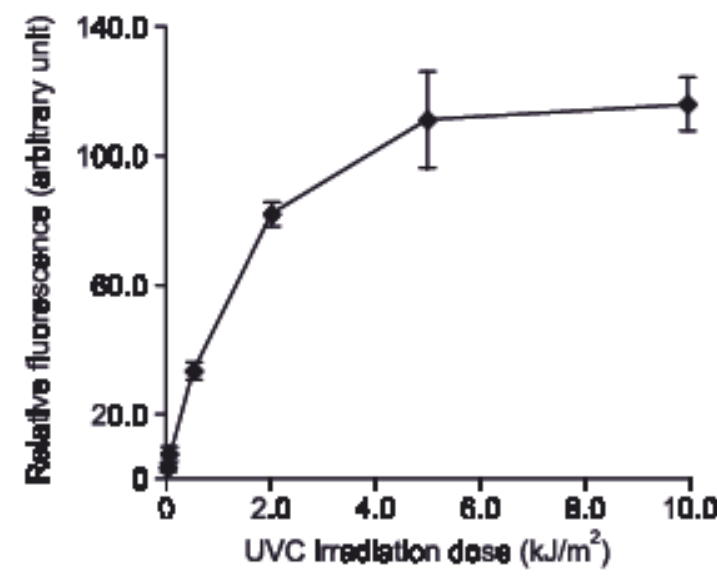

Figure 2. Oxidative species induced by UVC irradiation in Vero 76 cells. Cells labeled with 2-7'-dichlorodihydro-fluorescein diacelate $(20 \mu \mathrm{M})$ were irradialed with the indicated dose $\left(\mathrm{kJ} / \mathrm{m}^{2}\right)$ of UVC. After $5 \mathrm{~min}$, fluorescence emitted by the oxidative species was quantized with a spectrofluorometer. The excitation wavelength was $520 \mathrm{~nm}$, and the emission wavelength was $604 \mathrm{~nm}$.

Increase in intracellular ROS by UVC irradiation In an effort to identify the oxidative effect induced by UVC irradiation on Vero 76 cells, we incubated the cells with H2DCFDA - an intracellular ROS sensor (Figure 2). The relative fluorescence determined after incubation for 5 min indicated an excessive increase in the ROS in intact cells by UVC irradiation. Even at low and moderate doses of UVC irradiation $\left(0.5-2.0 \mathrm{~kJ} / \mathrm{m}^{2}\right)$, which are insufficient to induce a large increase in UVC-stimulated PLD activity in Figure $1 \mathrm{~A}$, the fluorescence increased to approximately 22 -fold of the basal fluorescence. The slope of fluorescence becomes attenuated at a dose of $2.0-5.0 \mathrm{~kJ} / \mathrm{m}^{2}$ and appears to be almost saturated at $5.0-10.0 \mathrm{~kJ} / \mathrm{m}^{2}$. The intracellular ROS observed by H2DCFDA had increased to 32 -fold of the basal ROS by a $10.0-\mathrm{kJ} / \mathrm{m}^{2}$ dose of UVC irradiation.

\section{Effect of calcium chelator and antioxidant}

In order to study the role of calcium and ROS in UVC-stimulated PLD activity in Vero 76 cells, we examined the effects of EGTA - an extracellular calcium chelator - and catalase - an antioxidant- on UVCstimulated PLD. BAPTA/AM and amifostine, an intracellular calcium chelator and a membrane permeable antioxidant, respectively, were also treated before UVC irradiation. As shown in Figure 3, both extracellular and intracellular calcium chelators as well as the antioxidant inhibited UVC-stimulated PLD activity. However, the extracellular effectors, namely, EGTA and catalase, markedly inhibited the PLD activity near the basal level, whereas BAPTA/AM and amifostine only partially inhibited the stimulated PLD activity by $26.3 \%$ and $62.4 \%$, respectively.

\section{Effects of protein kinase inhibitors on the UVC-stimulated PLD activity}

In order to identify the kinase-dependent signaling pathway, we examined PD098059, SB203581, wortmannin, genistein, and R032-0432 and GF 109203X that inhibit mitogen-activated protein kinase kinase 


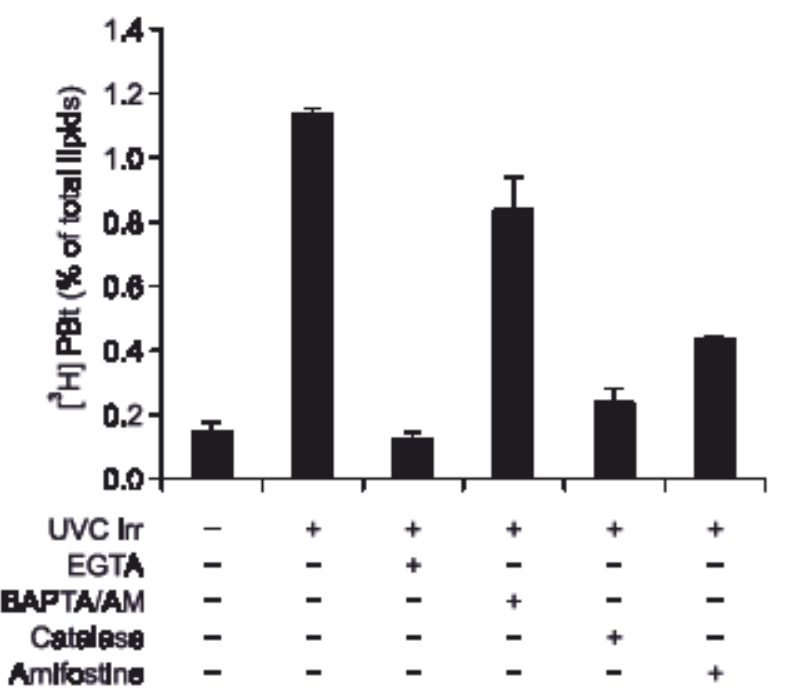

Figure 3. Effects of an antioxidant and a $\mathrm{Ca}^{2+}$ chelator on the UVC-stimulated PLD activity in Vero 76 cells. ['H] PAL-tabeled cells were preincubated with EGTA (2.5 mM, for $5 \mathrm{~min})$, BAPTA/AM $(100 \mu \mathrm{M}$, for $30 \mathrm{~min})$, catalase $(10,000 \mathrm{U} / \mathrm{ml}$, for $5 \mathrm{~min})$, or amifostine $(0.5 \mathrm{mg} / \mathrm{ml}$, for $24 \mathrm{~h}$ ) and then incubated for $30 \mathrm{~min}$ after UVC irradiation $\left(10 \mathrm{~kJ} / \mathrm{m}^{2}\right)$ in the presence of $0.3 \%$ of $n$-butanol. The radicactivity incorporated into PBt was measured as described under Materials and Methods. The data presented are the mean \pm SD in triplicate.

(MAPKK), P38 mitogen-activated protein kinase (P38MAPK), phosphatidyl inositol-3 kinase (PI3K), protein tyrosine kinase, and protein kinase $C$, respectively. As shown in Figure 4, PD098059 and SB203581 did not significantly inhibit PLD activity. Wortmanin and genistein partially inhibited the UVCstimulated PLD activity. However, the PKC inhibitors GF109203X and Ro32-0432 appeared to inhibit the PLD activity to the basal level. This effect of PKC inhibitors was confirmed by the downregulation of PKC with phorbol ester (van Blitterswijk et al., 1991). The accumulation of PBt by UVC irradiation was almost eliminated by the preincubation of $100 \mathrm{nM}$ PMA for $18 \mathrm{~h}$. This study on the inhibitor suggests that PKC plays a key role in UVC-stimulated PLD activity in Vero 76 cells.

\section{Effect of UVC irradiation on the PLD isoforms transfected in Vero 76 cells}

The PLDs in Vero 76 cells were blotted with antiPLD1 and anti-PLD2 antibodies (Figure 5A). Endogenous PLDs in Vero 76 cells were not detected clearly; however, the Vero 76 cells that were transfected by human PLD1b (hPLD1b) and murine PLD2 (mPLD2) showed strong PLD bands. In vitro PLD activity of Vero 76 cells by using $\left[{ }^{3} \mathrm{H}\right]$ DPPC was significantly increased by the transfection of hPLD1b and mPLD2 (Figure 5B).

In order to identify the subspecies of PLD that

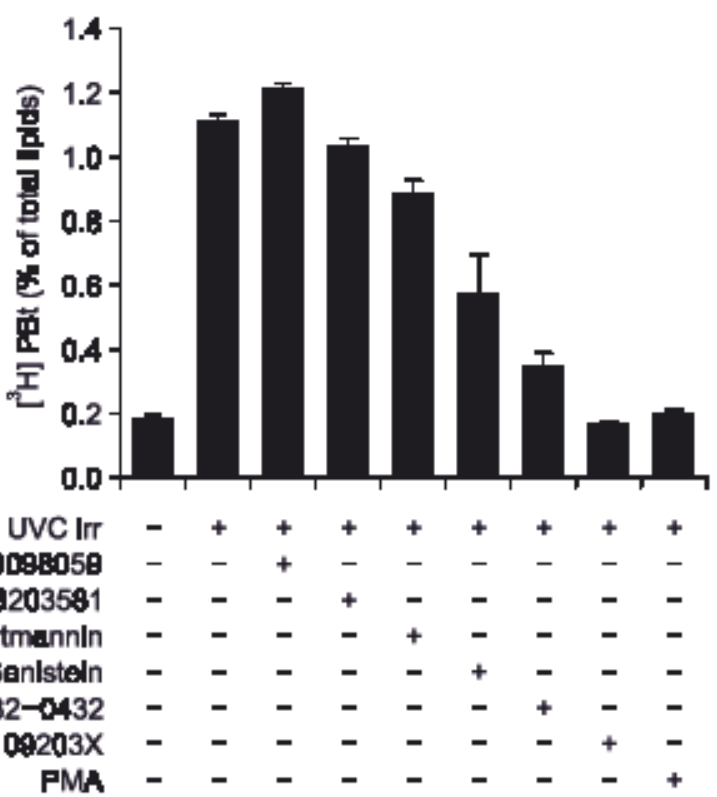

Figure 4. Eflects of kinase inhibitors on the UVC-stimulated PLD activity in Vero 76 cells. [ ${ }^{3} \mathrm{H}$ ] PAL-Jabeled cells were preincubated with PD098059 (10 $\mu \mathrm{M})$, SB203581 (10 $\mu \mathrm{M})$, wortmanin (100 nM), genistein $(100 \mu \mathrm{M})$, Ro32-0432 $(100 \mathrm{nM})$, and GF109203X (10 $\mu \mathrm{M})$ for $30 \mathrm{~min}$ and then incubated for $30 \mathrm{~min}$ after UVC irradiation $\left(10 \mathrm{~kJ} / \mathrm{m}^{2}\right)$ in the presence of $0.3 \%$ of $n$-butanol. For PMA pretreatment, [ $\left.{ }^{3} \mathrm{H}\right]$ PAL-tabeled cells were preincubated with PMA $(200 \mathrm{nM})$ for $18 \mathrm{~h}$. The radioactivity incorporated into PBt was measured as described under Malerials and Methods. The data presented are the mean \pm SD in triplicate.

respond to UVC irradiation, we examined the effect of UVC irradiation on the hPLD1b- and mPLD2- expressed Vero 76 cells (Figure $5 \mathrm{C}$ ). The intact cell PLD activity of the PLD2-expressed cells greatly increased at a dose of $0.5-3.0 \mathrm{~kJ} / \mathrm{m}^{2}$ UVC irradiation, while mPLD2 activity increased moderately to $2 \%$ when compared with $1.2 \%$ of untransfected Vero 76 cells at $10 \mathrm{~kJ} / \mathrm{m}^{2}$ UVC irradiation. However, hPLD1-expressed cells did not surpass the untransfected UVC-stimulated PLD activity. The mPLD2-transfected cells were sensitive to UVC irradiation, whereas the hPLD1-expressed cells appeared to be unaffected by UVC.

\section{PKC interaction with PLD transfected in Vero 76 cells}

Figures 4 and 5 suggest that PKC and PLD2 were responsible for the UVC-induced PLD activation observed in Vero 76 cells. The PKC inhibitors G109203X and Ro32-0432 have been evaluated to be inhibitors of the conventional PKC family. Ro32-0432, in particular, showed a significant selectivity for PKC $\alpha$ and PKC $\beta$ (Wilkinson et al., 1993). Therefore, we examined the interaction between PLD and PKC by using monoclonal PKC (MC5 clone) antibody specific for $\alpha, \beta$ and $\gamma$ isoforms. Cell lysates transfected 
A

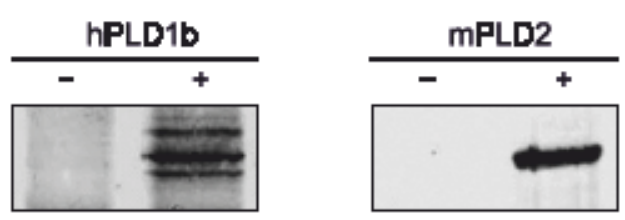

B

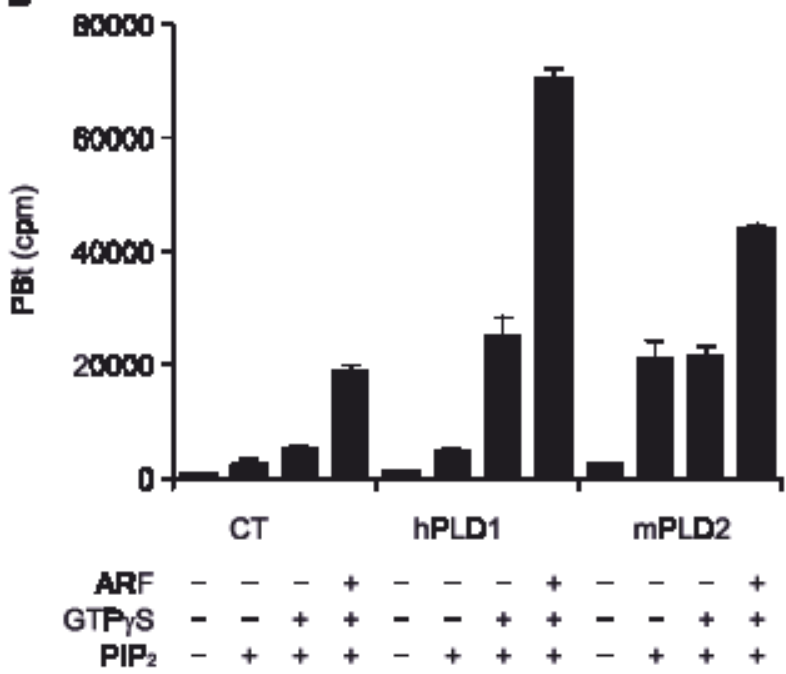

C

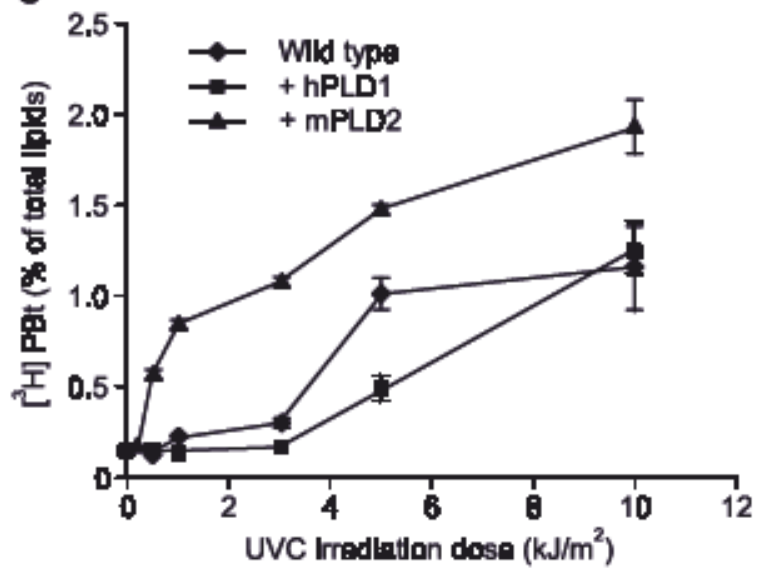

Figure 5. Effect of transfection of PLD isoforms in Vero 76 cells. Western blotting and ARF-dependent PLD assay were carried out with cell hysates prepared from the wild-type $(-)$, hPLD1b, or mPLD2-transfected( + ) Vero 76 cells. (A) Cell lysates $(50 \mu \mathrm{g})$ were separaled and blotted with anti-PLD1 and

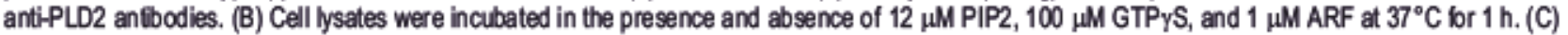
Vero 76 cells that were transfected with hPLD1b or mPLD2 were radiolabeled, irradiated with the indicated dose of UVC, and then incubated for 30 min in the presence of $0.3 \%$ of $n$-butanol. The radioactivity incorporated into PBt was measured as described under Malerials and Methods. The data presented are the mean \pm SD in triplicale.

with hPLD1 or mPLD2 were immunoprecipitated with PLD1 or PLD2 antibody, respectively, and immunoblotted with MC5 clone antibody (Figure 6A). The level of PKC coimmunoprecipitated with transfected mPLD2 dramatically increased after $10 \mathrm{~min}$ upon UVC irradiation, whereas the level of PKC with hPLD1 minimally increased in the same time period. This time course of maximum mPLD2 incorporation with PKC appeared to be similar to the second period of incubation interval (5-10 min), which produced a major PLD stimulation (Figure 1B).

Considering the inhibitory effects of EGTA and catalase as observed in Figure 3, translocation of PKC by an interaction with MPLD2 would be prevented in the absence of extracellular calcium or by the elimination of ROS from the plasma membrane. Figure 6B illustrates the localization of PKC $\alpha$ and PKC $\beta$ through a Western blot analysis with antiPKC $\alpha$ - or PKC $\beta$-specific antibody. After UVC irradiation, we separated the membrane fraction from the cytosolic fraction by ultracentrifugation. In the control cells, PKC $\alpha$ and PKC $\beta$ were found to be located in the cytosolic fraction; however, PKC $\alpha$ and PKC $\beta$ were translocated into the membrane fraction by UVC irradiation (Figure 6B). However, when EGTA or catalase was added to the reaction media, UVC-induced translocation of PKCs to the membrane fraction was prevented. On the other hand, Ro32-0432 - the PKC inhibitor - did not prohibit the translocation of PKC $\alpha$ and PKC $\beta$ but blocked the UVC-stimulated PLD activation, probably blocking the PKC phosphorylation of PLD2 by Ro32-0432 (Figure 4). From these observations, we can postulate that PKC $\alpha$ and PKC $\beta$ are translocated to the membrane fraction by excessive oxidative stress in the presence of extracellular calcium. This enables PKC interaction with PLD2 in order to stimulate PLD2 activity via phosphorylation of the enzyme.

\section{Phosphorylation of PL2 by UVC irradiation on $\mathrm{MPLD} 2$}

PKC is known as a multifunctional protein kinase that phosphorylates serine and threonine residues in many target proteins. Generally, serine and threonine residues of PLD2 are known to be phosphor- 
A
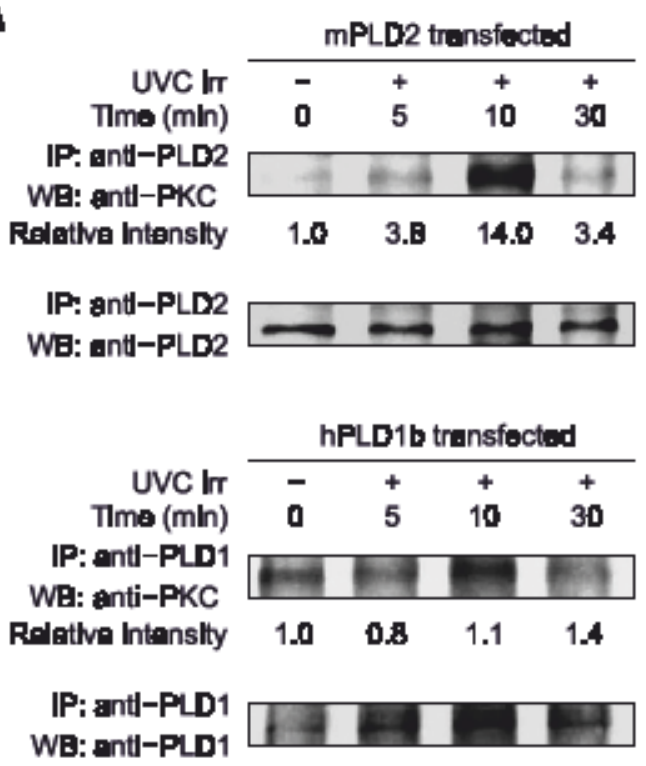

$\mathbf{B}$

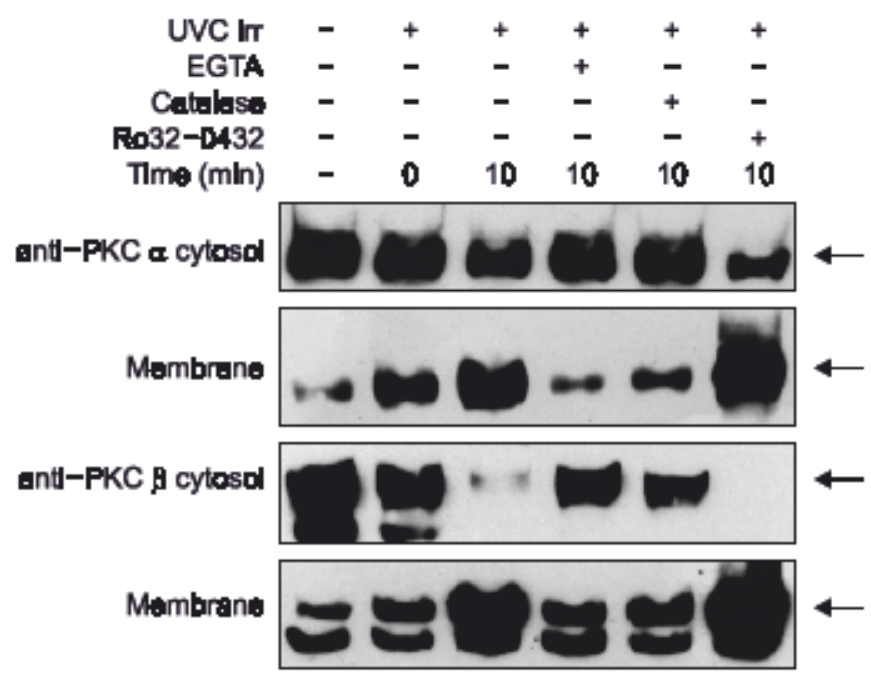

Figure 6. Translocation of PKC after UVC irradiation in PLD-transfected Vero 76 cells. (A) Vero 76 cells transfected with hPLD1b or mPLD2 were incubated for the indicated time period after UVC irradiation. PKC that was associated with PLD1 and PLD2 was immunoprecipitated by anti-PLD1 and anti-PLD2, respectively, and blotted with anti-PKC (MC5). (B) Vero 76 cells transfected with mPLD2 were preincubaled with EGTA (2.5 mM, for 5 min), catalase $(10,000 \mathrm{U} / \mathrm{ml}$, for $5 \mathrm{~min})$, or GF109203X (10 $\mu \mathrm{M}$, for $30 \mathrm{~min})$ and incubated for the indicated fime period after UVC irradiation $\left(10 \mathrm{~kJ} / \mathrm{m}^{2}\right)$. The cytosolic and membrane fractions were separated as described under Materials and Methods. The amount of PKC $\alpha$ and $\beta$ localed in the membrane and cytosolic fractions were determined by Westem blotting using the ant-PKC $\alpha$ or $\beta$ anfibody.

ylated and dephosphorylated by the physiological state of the cells (Chen and Exton, 2004). Since PKC transiently interacted with PLD2 and activated PLD activity after UVC irradiation, detection of the phosphorylation of the serine and threonine residues in PLD2 could be verified. Vero 76 cells transfected with the MPLD2 gene tagged to a hemagglutin (HA) epitope were lysed at the indicated time after UVC irradiation. This cell homogenate was then immunoprecipitated with anti-HA antibody and blotted by anti-phosphoserine- or anti-phosphothreonine-specific antibody. The time-dependent phosphorylation of PLD2 is presented in Figure 7. After UVC irradiation, the basal level of phosphorylation of mPLD2 appeared to show a marked increase at approximately $5 \mathrm{~min}$. However, the phosphorylation level decreased to the basal level within $30 \mathrm{~min}$. This transient phosphorylation could be compared with the time courses of PLD stimulation (Figure 1B) and PKC incorporation with mPLD2 (Figure 6A). The time-dependent phosphorylation of the serine and threonine residues in mPLD2 indicates that the phosphorylation state is the activated state of PLD induced by UVC irradiation.

\section{Discussion}

In this study, we observed marked stimulation of

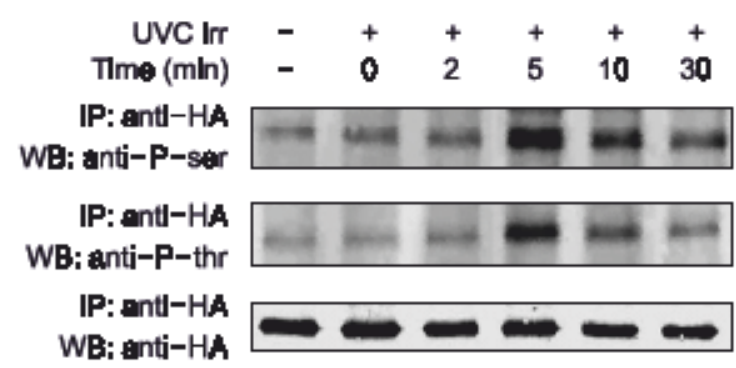

Figure 7. Transient phosphorylation of the transfected PLD2 after UVC irradiation. Cells transfected with mPLD2 DNA containing hemagglutin (HA) epitope were incubaled for the indicated time after UVC irradiation $\left(10 \mathrm{~kJ} / \mathrm{m}^{2}\right)$. The cell lysates were harvested and immunoprecipitated with ant-HA and blotted with anti-phospho-Ser and anti-phospho-Thr. The relative amount of phosphorylation of MPLD2 was determined by Western blotting.

PLD activity in Vero 76 cells by UVC irradiation (Figure 1). This stimulated PLD activity required significant amount of ROS produced by a $10 \mathrm{~kJ} / \mathrm{m}^{2}$ dose of UVC irradiation (Figure 2). The UVC-stimulated PLD was greatly dependent on the presence of extracellular calcium and was effectively inhibited by catalase (Figure 3). However, BAPTA/AM - an intracellular calcium chelator - and amifostine - an intracellular antioxidant - only partially inhibited the stimulated PLD activity. The influx of calcium into the 
intracellular space was not important since preincubation of a calcium ionophore, A23187, as well as several calcium channel inhibitors such as flunarizine and neomycin did not alter the UVC-stimulated PLD activity in Vero 76 cells (data not shown). Similarly, PLD activity stimulated by hydroperoxide (Lee et al., 2000; Servitja et al., 2000) or pervanadate (Oh et al., 2000) has been reported to be dependent on extracellular calcium. On the other hand, other stimulants of PLD activity, such as phorbol ester (Huang et al., 1992), $\alpha$-thrombin (Garcia et al., 1992), or oleate (Lee et al., 1998), are not dependent on extracellular calcium.

The PLD activity stimulated by UVC was effectively inhibited by the protein kinase $C$ inhibitors, namely, Ro32-0432 and G109203X (Figure 4). This PKC dependence was further confirmed by the downregulation of PKC. Other protein kinase inhibitors, such as wortmanin and genistein, exerted only slight inhibition on the UVC-stimulated PLD in the Vero 76 cells. Some PLD activities were reported to be dependent on tyrosine kinases, including P38 mitogen-activated protein kinase in cell lines such as bovine pulmonary artery endothelial cells (Natarajan et al., 2001) and PC12 cells (Banno et al., 2001).

The UVC upregulation of PLD2 activity in Vero 76 cells that were transfected with mPLD2 strongly suggests that endogenous PLD activity stimulated by UVC irradiation is probably the isoform of PLD2 (Figure 5). In particular, the exhibited mPLD2 activity increased its sensitivity toward UVC irradiation at relatively low doses in a range of $0.5-3.0 \mathrm{~kJ} / \mathrm{m}^{2}$, whereas hPLD1 did not exhibit sensitivity toward any doses of UVC irradiation (Figure $5 \mathrm{C}$ ).

The study of incorporation of PKC into the transfected mPLD2 revealed that PKC was transiently incorporated with mPLD2 at approximately $10 \mathrm{~min}$ and dissociated to a basal level after 30 min (Figure $6 \mathrm{~A}$ ). As shown in Figure 6B, PKC $\alpha$ and PKC $\beta$ were translocated upon UVC irradiation in the presence of calcium ions. Despite the translocation of PKC, blocking the UVC-stimulated PLD activity by preincubation of Ro32-0432 demonstrates the importance of the phosphorylation status of mPLD2. A study on the time-dependent phosphorylation of mPLD2 (Figure 7) revealed similar time courses of PKC incorporation and mPLD2 activation. The time required for maximum activation of endogenous PLD activity by UVC (Figure 1B) may be compared with the fime courses of mPLD2 activation and translocation. Recently, Hu and Exton reported a study of the phosphorylation of PLD1 stimulated by PMA compared with the status of time-dependent PLD1 activity and PKC $\alpha$ binding (Hu and Exton, 2003). They observed that PLD1 activity was maximized within $5 \mathrm{~min}$ and decreased to the basal level within
$30 \mathrm{~min}$. However, the phosphorylation of threonine residues in PLD1 and the incorporation of PKC were found to be interconnected, and they were phosphorylated even after $30 \mathrm{~min}$. This indicates that the phosphorylation status did not coincide with the transient stimulation of the PLD1 activity. In contrast to the PMA-induced PLD1 activation, the UVCstimulated mPLD2 activity in Vero 76 cells appears to coincide with the phosphorylation of PLD2 with the transient translocation of PKC to the membrane fraction. This relationship demonstrates the phosphorylation-dependent activation of mPLD2 by PKC. These data indicate that PLD2 activity in Vero 76 cells is selectively stimulated by UVC, and the phosphorylation status of PLD2 appears to coincide with the time course of the translocation of PKC ( $\alpha$ and $\beta)$ to the membrane fraction. Thus, our results demonstrate the involvement of the PKC pathway in the UVC-stimulated PLD activity in Vero 76 cells.

\section{Acknowledgement}

This work was supported by the Brain Korea 21 Program and by the Korea Science and Engineering Foundation (KOSEF) through the Center for Molecular Catalysis at the Seoul National University.

\section{References}

Banno Y, Wang S, Ito Y, Izumi T, Nakashima S, Shimizu T, Nozawa $Y$. Imvolvement of ERK and p38 MAP kinase in oxidative stress-induced phospholipase D activation in PC12 cells. Neuroreport 2001;12:2271-5

Brown HA, Gutowski S, Moomaw CR, Slaughter C, Stermweis BC. ADP-ribosylation factor, a small GTP-dependent regulatory protein, stimulates phospholipase $\mathrm{D}$ activity. Cell 1993;75:1137-44

Chahdi A, Choi WS, Kim YM, Beaven MA. Mastoparan selectively activates phospholipase D2 in cell membranes. J Biol Chem 2003;278:12039-45

Chen JS, Exton JH. Regulation of phospholipase D2 activity by protein kinase alpha. J Biol Chem 2004; 279:22076-83

Choi WS, Kim YM, Combs C, Frohman MA, Beaven MA. Phospholipases D1 and D2 regulate different phases exocytosis in mast cells. J Immunol 2002;168:5682-9

Colley WC, Sung TC, Roll R, Jenco J, Hammond SM, Altshuller Y, Bar-Sagi D, Morris AJ, Frohman MA. Phospholipase D2, a distinct phospholipase D isoform with novel regulatory properties that provokes cytoskeletal reorganization. Curr Biol 1997;7:191-201

Exton $\mathrm{JH}$. Phospholipase D-structure, regulation and function. Review of Physiology, Biochem \& Phamacol 2002;144: 1-94

Freyberg Z, Sweeney D, Siddhanta A, Bourgoin S, Frohman M, Shields D. Intracellular localization of phospholipase D1 
in mammalian cells. Mol Biol Cell 2001;12:943-55

Frohman MA, Sung TC, Morris AJ. Mammalian phospholipase D structure and regulation. Biochem Biophy Acta 1999;1439:175-86

Garcia JG, Fenton JW, Natarajan V. Thrombin stimulation of human endothelial cell phospholipase $D$ activity. Regulation by phospholipase $\mathrm{C}$, protein kinase $\mathrm{C}$, and cyclic adenosine 3'5'-monophosphate. Blood 1992;79:2056-67

Girotti AW. Lipid hydroperoxide generation, turnover, and effector action in biological systems. J Lipid Res 1998;39: $1529-42$

Girotti AW. Photosensitized oxidation of membrane lipids: reaction pathways, cytotoxic effects, and cytoprotective mechanisms. J Photochem Photobiol B 2001;63:103-13

Halliwell B, Gutteridge JMC. Free Radicals in Blology and Medicine. 3rd Ed. 1999 Oxford University

Hu T, Exton JH. Mechanisms of regulation of phospholipase D1 by protein kinase $\mathrm{C}$ alpha. J Biol Chem 2003;278:2348-55

Huang C, Wylle RL, Daniel LW, Cabot MC. Identification of phosphatidylcholine-selective and phosphatidylinositol-selective phospholipases $D$ in Madin-Darby canine kidney cells. J Biol Chem 1992;267:16859-65

Ito $Y$, Nakashima S, Nozawa $Y$. Hydrogen peroxide-induced phospholipase $\mathrm{D}$ activation in rat pheochromocytoma $\mathrm{PC} 12$ cells: possible imvolvement of $\mathrm{Ca}^{2+}$-dependent protein tyrosine kinase. J Neurochem 1997;69:729-36

Jang MJ, Lee M-J, Park H-Y, Bae YS, Min DS, Ryu SH, Kwak J-Y. Phosphorylation of phospholipase D1 and the modulation of its interaction with RhoA by cAMP-dependent protein kinase. Exp Mol Med 2004;36;172-8

Jung K, Koh E, Choi M-U. Catalytic properties of phospholipase $\mathrm{D}$ using phosphatidic acid as an activator. Bull Korean Chem Soc 1989;10:585-600

Kim C, Choi M-U, Choi MS. Alteration of oleate-phospholipase D activation in some cellines after irradiation. J Korean Cancer Assoc 1997;29:944-53

Kim J, Min G, Bae Y-S, Min DS. Phospholipase D is involved in oxidative stress-induced migration of vascular smooth muscle cells via tyrosine phosphorylation and protein kinase C. Exp Mol Med 2004;36:103-9

Kim Y-R, Cha H-Y, Lim K, Hwang B-D, Hoe K-L, Namgung U, Park S-K. Activation of epidermal growth factor receptor is responsible for pervanadate-induced phospholipase D activation. Exp Mol Med 2003;35:118-24

Lee BD, Kim JH, Lee SD, Km Y, Suh PG, Ryu SH. Hydrogen peroxide-induced phospholipase D2 activation in lymphocytic leukemic L1210 cells. J Leukoc Biol 2000; 67:630-6

Lee SY, Park NG, Choi MU. Effects of mastoparan B and its analogs on the phospholipase D activity in L1210 cells. FEBS Letter 1998;432:50-4

Lee SY, Yeo E-J, Choi M-U. Phospholipase D activity in L1210 cells: A model for oleate-activated phospholipase $D$ in intact mammalian cells. Biochem Biophys Res Comm 1998; 244:825-31
Liscovitch M, Czarmy M, Fiucci G, Lavie Y, Tang X. Localization and possible functions of phospholipase D isozymes. Biochim Biophys Acta 1999;1439:245-63

Min DS, Kim EG, Exton JH. Involvement of tyrosine phosphorylation and protein kinase $\mathrm{C}$ in the activation of phospholipase $\mathrm{D}$ by $\mathrm{H}_{2} \mathrm{O}_{2}$ in Swiss $3 \mathrm{~T} 3$ fibroblasts. $\mathrm{J}$ Biol Chem 1998;273:29986-94

Min DS, Shin E-Y, Kim EG. The P38 MAPK is involved in stress induced phospholipase $\mathrm{D}$ activation in vascular smooth muscle cells. Exp Mol Med 2002;34:38-43

Natarajan V, Scribner WM, Morris AJ, Roy S, Vepa S, Yang J, Wadgaonkar R, Reddy SP, Garcia JG, Parinandi NL. Role of p38 MAP kinase in diperoxovanadate-induced phospholipase $D$ activation in endothelial cells. Am J Physiol Lung Cell Mol Physiol 2001;281:435-49

Natarajan V, Vepa S, Verma RS, Scribner WM. Role of protein tyrosine phosphorylation in $\mathrm{H}_{2} \mathrm{O}_{2}$-induced activation of endothelial cell phospholipase D. Am J Physiol 1996;271: $400-8$

Oh SO, Hong JH, Kim YR, Yoo HS, Lee SH, Lim K, Hwang BD, Exton JH, Park SK. Regulation of phospholipase D2 by $\mathrm{H}_{2} \mathrm{O}_{2}$ in $\mathrm{PC} 12$ cells. J Neurochem $2000 ; 75: 2445-54$

Rydzewska G, Jurkowska G, Gabryelewicz A. Phospholipase $D$ mediated transphospatidylation as a possible new pathway of ethanol metabolism in isolated rat pancreatic acini. J Physiol Pharmacol 1996;47:385-95

Sarn E, Pardo R, Fensome-Green A, Cockcroft S. Endogenous phospholipase D2 localizes to the plasma membrane of RBL-2H3 mast cells and can be distinguished from ADP ribosylation factor-stimulated phospholipase D1 activity by its specific sensitivity to oleic acid. Biochem J 2003; 369:319-29

Servitja JM, Masgrau R, Pardo R, Sarri E, Picatoste F. Effects of oxidative stress on phospholipid signaling in rat cultured astrocytes and brain slices. J Neurochem 2000;75: 788-94

Shen JZ, Zheng XF, Wei EQ, Kwan CY. Evidence against inhibition of sarcoplasmic reticulum $\mathrm{Ca}^{2+}$-pump as mechanism of $\mathrm{H}_{2} \mathrm{O}_{2}$-induced contraction of rat aorta. Acta Pharmacol Sin 2001;22:498-504

Taher MM, Mahgoub MA, Abd-Efattah AS. Redox regulation of signal transduction in vascular smooth muscle cells: thiol oxidizing agents induced phospholipase $\mathrm{D}$. Biochem Mol Biol Int 1998;46:619-28

van Blitterswijk WJ, Hilkmann $\mathrm{H}$, de Widt $\mathrm{J}$, van der Bend $\mathrm{RL}$. Phospholipid metabolism in bradykinin-stimulated human fibroblasts. I. Biphasic formation of diacylglycerol from phosphatidylinositol and phosphatidylcholine, controlled by protein kinase C. J Biol Chem 1991;266:10337-43

Weigel G, Griesmacher A, Toma CD, Baecker C, Heinzl H, Mueller MM. Endothelial eicosanoid metabolism and signal transduction during exposure to oxygen radicals injury. Thromb Res 1997;87:363-75

Wilkinson SE, Parker PJ, Nixon JS. Isoenzyme specifidty of bisindolymaleimides, selective inhibitors of protein kinase $\mathrm{C}$. Biochem J 1993:294:335-7 